\title{
A 2000-year annual record of snow accumulation rates for Law Dome, East Antarctica
}

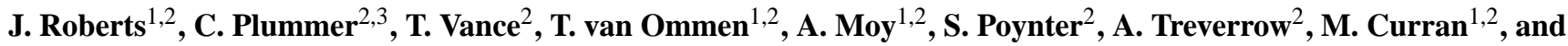 \\ S. George ${ }^{2,4}$ \\ ${ }^{1}$ Australian Antarctic Division, Kingston, Tasmania 7050, Australia \\ ${ }^{2}$ Antarctic Climate \& Ecosystems Cooperative Research Centre, University of Tasmania, \\ Hobart, Tasmania 7001, Australia \\ ${ }^{3}$ Institute for Marine and Antarctic Studies, University of Tasmania, Hobart, Tasmania 7001, Australia \\ ${ }^{4}$ NCAS-Climate, Department of Meteorology, University of Reading, Reading, UK
}

Correspondence to: J. Roberts (jason.roberts@aad.gov.au)

Received: 21 October 2014 - Published in Clim. Past Discuss.: 28 November 2014

Revised: 31 March 2015 - Accepted: 9 April 2015 - Published: 5 May 2015

\begin{abstract}
Accurate high-resolution records of snow accumulation rates in Antarctica are crucial for estimating ice sheet mass balance and subsequent sea level change. Snowfall rates at Law Dome, East Antarctica, have been linked with regional atmospheric circulation to the mid-latitudes as well as regional Antarctic snowfall. Here, we extend the length of the Law Dome accumulation record from 750 years to 2035 years, using recent annual layer dating that extends to $22 \mathrm{BCE}$. Accumulation rates were calculated as the ratio of measured to modelled layer thicknesses, multiplied by the long-term mean accumulation rate. The modelled layer thicknesses were based on a power-law vertical strain rate profile fitted to observed annual layer thickness. The periods 380-442, 727-783 and 1970-2009 CE have aboveaverage snow accumulation rates, while 663-704, 933-975 and 1429-1468 CE were below average, and decadal-scale snow accumulation anomalies were found to be relatively common (74 events in the 2035-year record). The calculated snow accumulation rates show good correlation with atmospheric reanalysis estimates, and significant spatial correlation over a wide expanse of East Antarctica, demonstrating that the Law Dome record captures larger-scale variability across a large region of East Antarctica well beyond the immediate vicinity of the Law Dome summit. Spectral analysis reveals periodicities in the snow accumulation record which may be related to El Niño-Southern Oscillation (ENSO) and Interdecadal Pacific Oscillation (IPO) frequencies.
\end{abstract}

\section{Introduction}

The short and sparse instrumental record in the high latitudes of the Southern Hemisphere means investigating long-term precipitation variability in this region is difficult without access to appropriate proxy records. Antarctic ice core data can provide suitable local measurements for annual precipitation; however, in order to derive accurate snow accumulation rates, snowfall must be high enough to resolve annual layering where deposition noise due to surface processes exists. Additionally, layer thinning from ice flow and snow densification must be suitably constrained. Annual layering provides a record of the net snow input at the site which is the sum of annual snow accumulation rate, the transport of wind blown surface snow and losses through ablation. Due to the lack of melt and relatively low wind speeds at the ice-coring site, evaporation and wind losses are expected to make a minor contribution to long-term variability and are neglected.

Law Dome (Fig. 1) is a small independent icecap in East Antarctica with a maritime climate (Morgan et al., 1997) yielding sufficiently high snow accumulation rates to allow for annual layer resolution back to $22 \mathrm{BCE}$ (including a year 0 in the calendar). Law Dome is separated from the submarine-based Aurora Subglacial Basin (Roberts et al., 2011) by the Vanderford Trench and associated Totten and Vanderford glacier systems. Consequently, ice flow at Law Dome is largely independent of the East Antarctic ice sheet and orography results in a strong east-west snow accumulation gradient (Morgan et al., 1997). 


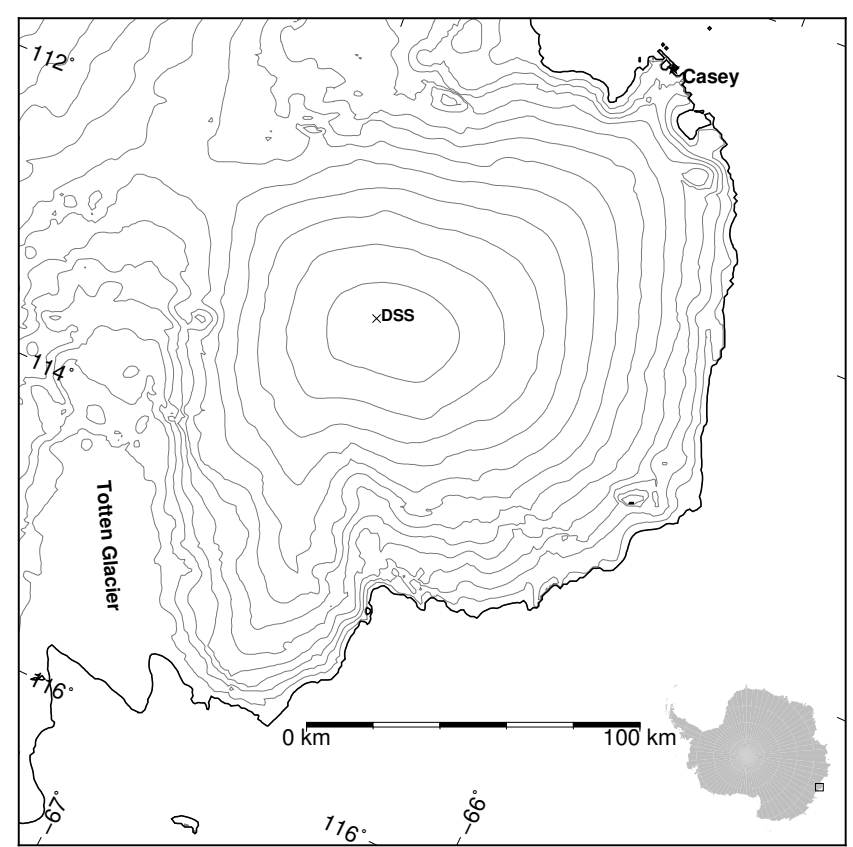

Figure 1. Law Dome, East Antarctica and the location of the Dome Summit South (DSS) borehole. Also shown are $100 \mathrm{~m}$ surface elevation contours from Bamber et al. (2009).

The principal ice core from Law Dome is the Dome Summit South (DSS) core $\left(66.7697^{\circ} \mathrm{S}, 112.8069^{\circ} \mathrm{E}, 1370 \mathrm{~m}\right.$ elevation) which was drilled approximately $4.7 \mathrm{~km} \mathrm{SSW}$ of the dome summit (Morgan et al., 1998) between 1987 and 1993. This site was selected for its favourable bedrock topography and sufficiently low surface temperatures (mean annual average of $-21.8^{\circ} \mathrm{C}$ ) which precludes summer melt (Morgan et al., 1997). The annual snow accumulation rate at DSS is $0.68 \mathrm{~m} \mathrm{yr}^{-1}$ IE (van Ommen et al., 2004, where IE stands for ice equivalent using an ice density of $917 \mathrm{~kg} \mathrm{~m}^{-3}$ to convert between $\mathrm{kg} \mathrm{m}^{-2} \mathrm{yr}^{-1}$ of water and the ice equivalent). This allows sub-annual resolution of water stable isotopes and trace ions. The DSS record has been updated incrementally with short cores drilled in subsequent years providing a complete 2035-year record spanning 22 BCE to 2012 CE.

Coastal Antarctic ice core records with high resolution are being used increasingly to reconstruct specific aspects of Southern Hemisphere climate. For example, climate modes such as the Southern Annular Mode (SAM), the El NiñoSouthern Oscillation (ENSO) and the Interdecadal Pacific Oscillation (IPO) have been reconstructed using annual layer-counted ice core records from Law Dome and elsewhere (Vance et al., 2013, 2015; Abram et al., 2014). Additionally, Law Dome has provided rainfall proxies for both eastern Australia (Vance et al., 2013) (1000 years) and southwest Western Australia (van Ommen and Morgan, 2010) (750 years). The south-west Western Australian (SWWA) rainfall proxy occurs via a direct precipitation oscillation between Law Dome and SWWA, as a result of spatially coherent, meridional wind patterns that push cool-dry or warm-moist air to either Law Dome or SWWA. Precipitation oscillation has been related to long-term variability in the zonal wave-number three (ZW3) pattern, injecting a meridional component to the dominant westerly wind stream in the Southern Hemisphere (Raphael, 2004; van Ommen and Morgan, 2010).

This study extends the length of the Law Dome annual snow accumulation rate record from 750 years (van Ommen and Morgan, 2010) to greater than 2000 years and increases the instrumental overlap (and therefore calibration) period by 7 years (or 26\%) to span 1979-2012 CE.

\section{Law Dome ice cores}

Four ice cores from the Dome Summit South (DSS) site at Law Dome were used to construct a composite snow accumulation rate record. The main DSS core (DSS-main) is augmented in the upper portion by splicing three other ice cores: DSS99, DSS97 and DSS1213, which cover the epochs 18411887, 1888-1988 and 1989-2012 CE, respectively. DSS97 and DSS99 replace sections of the upper part of the DSSmain core that were subject to poor core quality due to a combination of melt infiltration from thermal drilling in firn and drill performance issues in the changeover to electromechanical drilling deeper down. This composite record extends a previous compilation from a series of short overlapping firn cores drilled in 2001, 2008 and 2009 (Plummer et al., 2012) and shows good replication of stable isotope signals during the period of overlap with the previous record. Specifically, the root mean squared difference between the layer thicknesses is $3 \%$, consistent with previous findings of a strong correlation $\left(r^{2} \sim 0.95\right)$ between annual ice thickness at the DSS site obtained from shallow firn cores (van Ommen and Morgan, 2010), due to the large snow accumulation rate relative to surface relief at the site.

The $1195.6 \mathrm{~m}$ DSS-main ice core record is dated by identifying annual layers in the seasonally varying water stable isotope ratios $\left(\delta^{18} \mathrm{O}\right.$ and $\left.\delta \mathrm{D}\right)$. Annual boundaries are defined by the peak of the summer isotope maximum, which has been identified as occurring on average around 10 January (van Ommen and Morgan, 1997). The isotope layer counting is augmented by seasonally varying trace ions to a depth of $796.138 \mathrm{~m}$, which corresponds to 22 BCE and shows excellent agreement with the dating of major volcanic events (Plummer et al., 2012). Dating error is small; \pm 1 year prior to $894 \mathrm{CE}$ and reaches a maximum uncertainty of $+4 /-7$ years at $22 \mathrm{BCE}$, which reflects ambiguities in the interpretation of the record (Plummer et al., 2012). The uncertainty estimate allows $22 \mathrm{BCE}$ to be a maximum of 7 years older or 4 years younger than dated. 


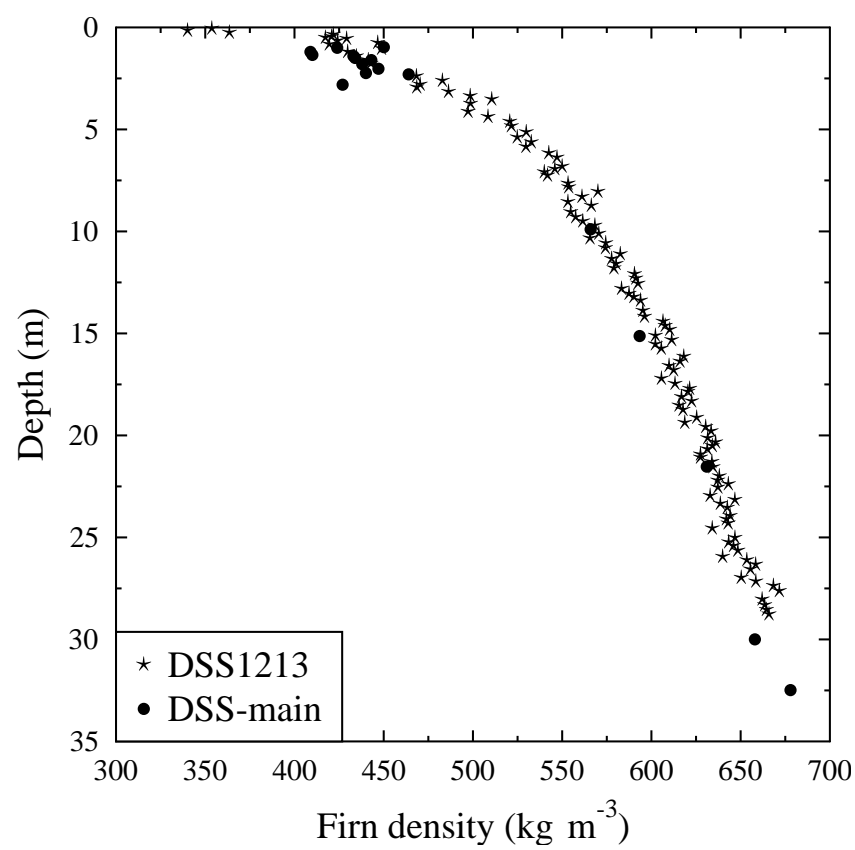

Figure 2. Firn density from the DSS-main and DSS1213 ice cores as a function of physical depth.

All depths (except Fig. 2) and annual layer thicknesses are reported as ice equivalent depth $(z)$, measured downward from the ice surface and calculated from the physical depth $\left(z^{\prime}\right)$ using

$z=\int_{0}^{z^{\prime}} \rho(\eta) d \eta$,

where the density profile, $\rho(\eta)$, is based on an empirical fit to the DSS-main core measurements (van Ommen et al., 2004). Time independence of the density profile (Sorge's Law, Paterson, 1994) is confirmed by the close correspondence between the density profiles from DSS-main and DSS1213 (separated in time by 15 years), as shown in Fig. 2.

\section{Accumulation history}

As firn is advected deeper into the ice sheet due to burial by subsequent snowfall and the bulk downward and outward flow of the ice sheet, the annual layers thin as a result of the vertical velocity gradient (the vertical strain rate). This thinning can be mathematically modelled and a correction factor applied if the vertical strain rate profile is known or can be estimated. A correction was applied to the composite record using coefficients modelled from the DSS-main core, which provided more robust estimates than the shorter records as the extra length damps the influence of short-duration fluctuations.

Ice thinning is modelled by applying a calculated vertical strain rate profile to a layer of initial thickness equal to the long-term average annual snow accumulation rate. The actual snow accumulation rate for any year (and corresponding depth) is then estimated as the ratio of the actual annual layer thickness relative to the modelled layer thickness multiplied by the long-term average annual snow accumulation rate,

$a(t)=a \times \frac{\lambda(t)}{\Lambda(t)}$,

where $a(t)$ is the annual snow accumulation rate for year $t$, $a$ is the long-term annual snow accumulation rate, $\lambda(t)$ is the observed annual layer thickness for year $t$ and $\Lambda(t)$ is the corresponding modelled annual layer thickness based on the long-term annual snow accumulation rate and the vertical strain rate profile. This method is unable to distinguish between a constant vertical strain rate or a linear trend in snow accumulation. Therefore, it is assumed that any change in layer thickness is due only to the vertical strain and that there is no long-term trend in snow accumulation rate.

Two accumulation histories, each corrected using a different vertical strain profile are compared. The vertical strain rate models used are (i) a piece-wise linear model (Dansgaard and Johnsen, 1969) and (ii) a power-law model (Lliboutry, 1979).

\subsection{Piece-wise linear vertical strain rate model}

The effects of layer thinning due to vertical strain rate can be accounted for by linear least squares fitting of a Dansgaard and Johnsen (1969) model to the ice equivalent annual layer thickness data as a function of ice equivalent depth. This model has two distinct regions: a lower region with a linear increase in vertical strain rate from zero at the base of the ice sheet and an overlying region of constant vertical strain rate. Integration of such a strain rate profile yields a vertical velocity profile with corresponding quadratic and linear segments. Previous modelling of the layer thinning for the DSS-main core (Morgan et al., 1997), using a Dansgaard and Johnsen relation, places the transition between these regions at a depth of $839 \mathrm{~m}$ (ice equivalent), somewhat below the $774 \mathrm{mIE}$ maximum depth of the composite record in this study. Consequently, the annual layer thickness model requires just two free parameters: the long-term annual snow accumulation rate and the constant vertical strain rate. These are estimated from the intercept and slope, respectively, of a least squares fit to the ice equivalent layer thickness as a function of ice equivalent depth.

The long-term average snow accumulation rate calculated from the layer thickness model applied to the DSS-main core is $6.80 \times 10^{-1} \pm 4.0 \times 10^{-3}$ ( 1 standard error) $\mathrm{m} \mathrm{yr}^{-1} \mathrm{IE}$ and the vertical strain rate is $6.32 \times 10^{-4} \pm 7.8 \times 10^{-6} \mathrm{yr}^{-1}$. The fit to the annual layer thickness data is shown in Fig. 3a and the snow accumulation rate time series in Fig. 4a. A smoothed snow accumulation rate time series using a Gaussian lowpass filter with width $\sigma=2.99$ years (equivalent half power width 10 years) is also shown. 

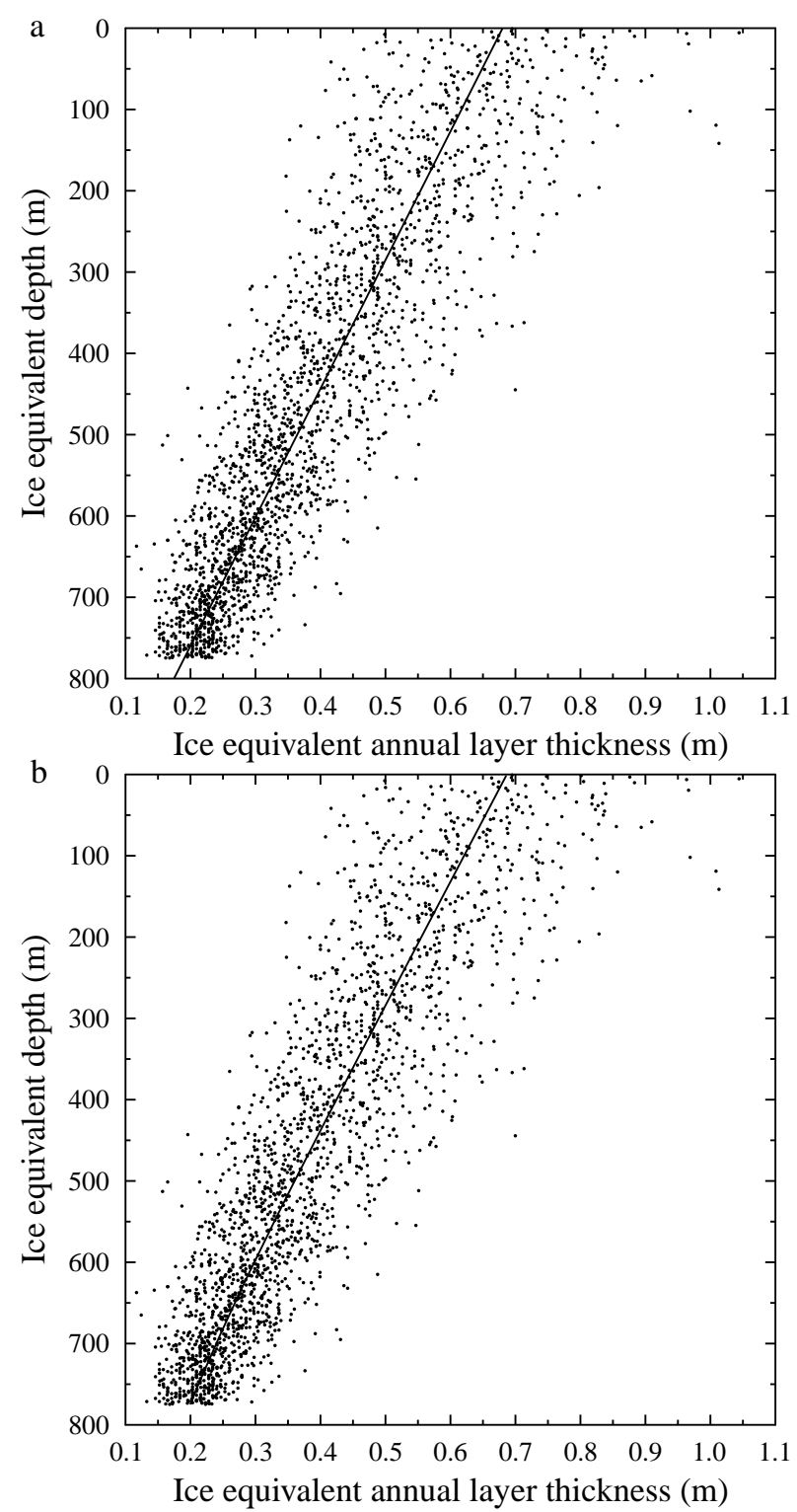

Figure 3. (a) Piece-wise linear fit to the annual layer thickness data and (b) power-law fit to the annual layer thickness data.

\subsection{Power-law vertical strain rate model}

The piece-wise linear model assumes that in areas near ice divides and dome summits the vertical strain rate depth profile is proportional to the horizontal velocity profile. This can be approximated by a linear lower segment and a constant upper segment (Dansgaard and Johnsen, 1969; Paterson, 1994). The depth profile of horizontal ice velocity at the DSS site was determined by repeated measurements of the borehole inclination following ice core drilling (Morgan et al., 1998). Fitting a power-law distribution (Lliboutry, 1979) to these horizontal velocities provides the basis for an improved vertical strain rate profile. As the temperature at the base of the borehole is below the in situ freezing point (Morgan et al.,

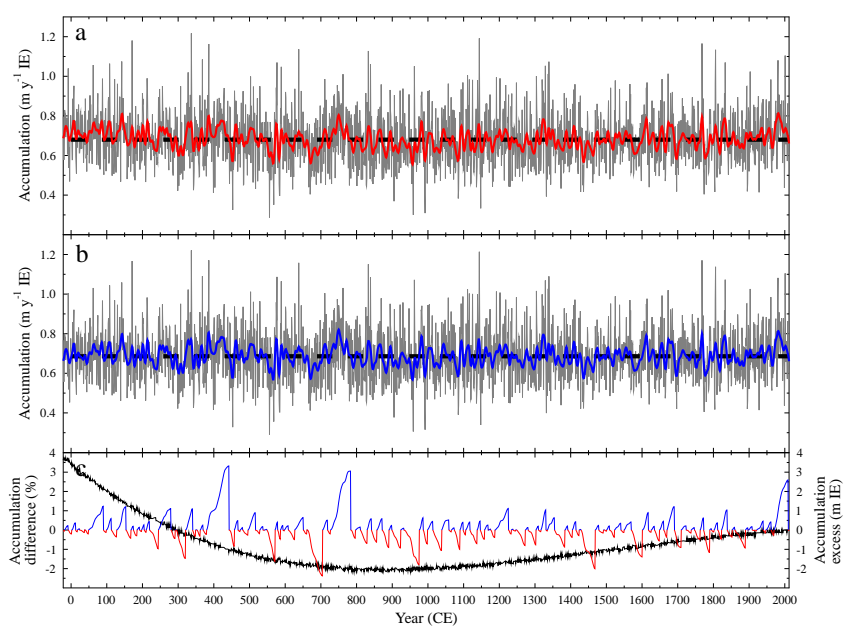

Figure 4. Annual (grey) and smoothed (coloured) snow accumulation rate history for $22 \mathrm{BCE}-2012 \mathrm{CE}$ based on (a) piece-wise linear vertical strain rate profile, with the long-term average snow accumulation rate of $0.680 \mathrm{~m} \mathrm{yr}^{-1} \mathrm{IE}$ shown (dashed horizontal), (b) power law vertical strain rate profile, with the long-term average snow accumulation rate of $0.686 \mathrm{~m} \mathrm{yr}^{-1}$ IE shown (dashed horizontal) and (c) difference in the smoothed accumulation histories (piece-wise linear-power-law vertical strain rate) normalised by the power-law vertical strain rate (black) and accumulation excess (Eq. 5) for positive (blue) and negative (red) periods.

1997), we ignore any terms representing melt or slip at the base of the ice sheet. The free parameters of the model are estimated by least squares fitting to the borehole displacements of Morgan et al. (1998). Data near the surface (depths less than $75 \mathrm{~m}$ ) were excluded as the upper section of the borehole was thermally drilled, and the corresponding large borehole diameter creates unreliable inclination data in this zone.

At depths below $800 \mathrm{~m}$, which is beyond the zone of interest for the present study, the flow regime at DSS becomes more complex due to the influence of the surrounding bedrock topography. Additionally, deformation rates, particularly the simple shear strain rate, are increasingly influenced by the development of large-scale polycrystalline anisotropy below $800 \mathrm{~m}$ (Morgan et al., 1998). In situations where ice flows over rough bedrock topography, the undisturbed flow in the upper portion of the ice sheet - that is relevant to the $2 \mathrm{kyr}$ accumulation record - can be approximated by assuming flow over an offset smoothed surface above the true base (Hutter, 1982). The (virtual) origin of the velocity profile corresponding to the smoothed bed is also offset from the physical origin of the velocity profile at the bedrock.

The borehole horizontal displacement $(D)$ is approximated using the shape function approach of Lliboutry (1979), namely a power-law profile with parameters determined from the model fit:

$$
D=C\left(1-\left(\frac{z}{H-z_{0}}\right)^{p}\right)
$$




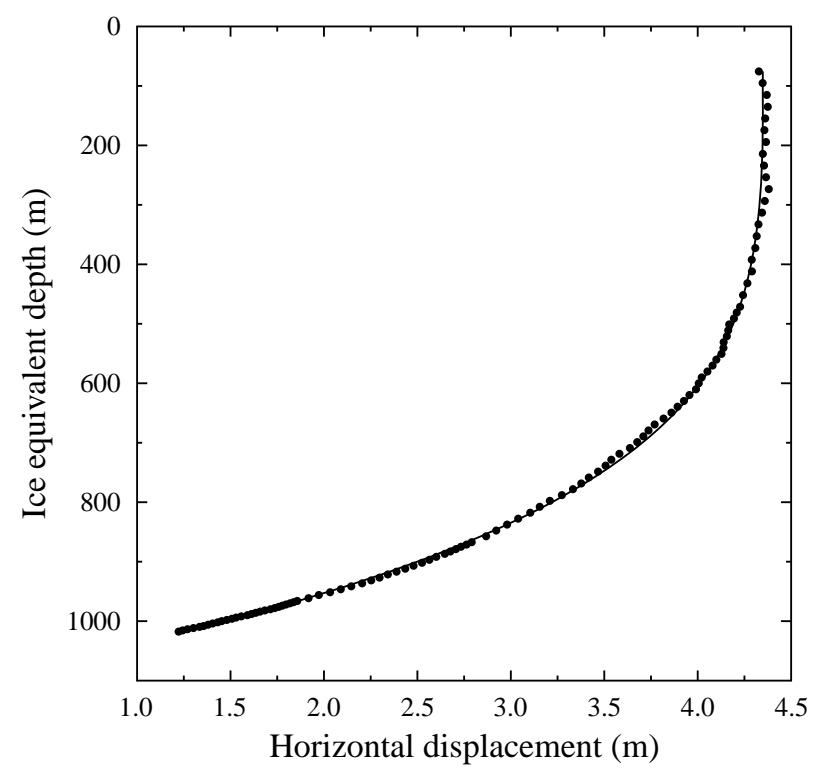

Figure 5. Power-law velocity profile fit (line) to the horizontal displacement data (dots) of Morgan et al. (1998).

where $z$ is the ice equivalent depth (m), $C=4.35 \pm 3.8 \times$ $10^{-3} \mathrm{~m}$ is an arbitrary scaling factor, the exponent of the power law is $p=4.19 \pm 0.025$ and $z_{0}=74.66 \pm 0.83 \mathrm{~m}$ represents the (positive) vertical displacement of the virtual velocity profile origin. The constant $H=1178.22 \mathrm{~m}$ represents the approximate ice equivalent ice sheet thickness from the displacement data. The horizontal displacement and the derived power law are shown in Fig. 5.

Integrating Eq. (3) with respect to depth yields the vertical velocity profile $v(z)$

$v(z)=a-s C\left(z-\frac{z}{p+1}\left(\frac{z}{H-z_{0}}\right)^{p}\right)$,

where $a$ is the long-term annual snow accumulation rate (in $\mathrm{m} \mathrm{yr}^{-1} \mathrm{IE}$ ) and $s$ is a scaling factor linearly related to the modelled vertical strain rate at the surface.

A least squares optimisation of the resulting vertical velocity profile to the observed annual layer thicknesses for the DSS-main core yields a long-term average annual snow accumulation rate of $6.86 \times 10^{-1} \pm 4.1 \times 10^{-3} \mathrm{~m} \mathrm{yr}^{-1} \mathrm{IE}$ and a surface vertical strain rate of $6.57 \times 10^{-4} \pm 8.1 \times 10^{-6}$, with the fit shown in Fig. 3b. The resulting snow accumulation time series, including a 10-year low-pass Gaussian filtered version, is shown in Fig. 4b.

\section{Discussion}

\subsection{Strain rate model}

The piece-wise linear vertical strain rate model assumes that flow near an ice divide is two-dimensional, so the vertical

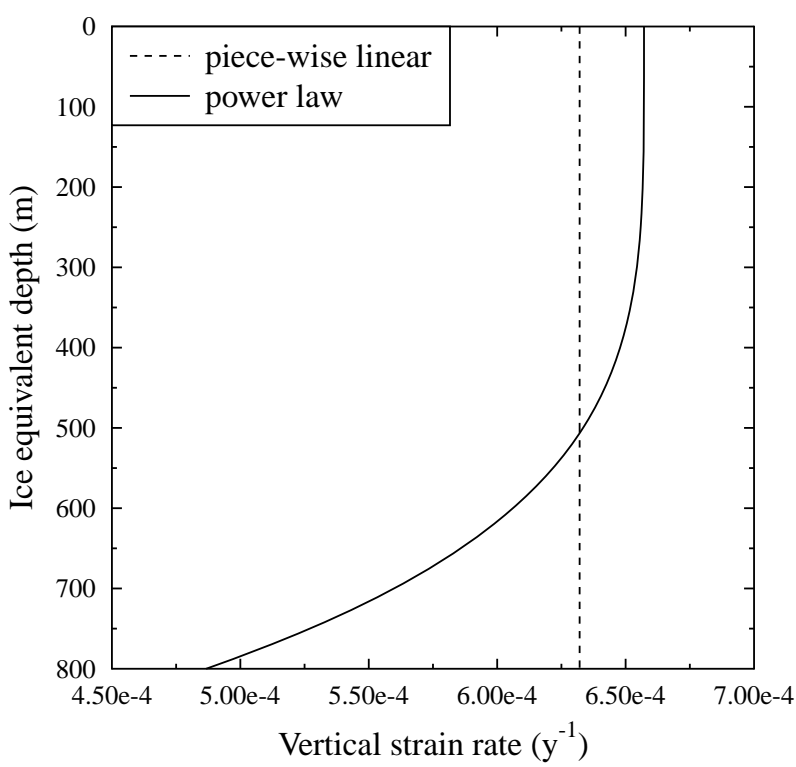

Figure 6. Vertical strain rates from the piece-wise linear and powerlaw models which were calculated using the annual layer thickness data.

strain rate profile with depth is proportional to the longitudinal derivative of the horizontal velocity profile. As described previously, the horizontal velocity profile is approximated by a linear lower segment and a constant upper segment. While this may be a good approximation for sites where the flow is two-dimensional, the DSS site is located $\sim 4$ ice thicknesses $(4.7 \mathrm{~km})$ from the Law Dome summit, where the flow is three-dimensional and slightly divergent (Morgan et al., 1998). Here, a power-law approximation to the horizontal velocity profile is more realistic. A comparison of the modelled vertical strain rate profiles at DSS (Fig. 6) show that the piece-wise linear model generates higher vertical strain rates at depth. This leads to an underestimation of annual layer thicknesses at depth, and correspondingly higher snow accumulation rates.

Furthermore, the nature of the least squares fit required to calibrate the piece-wise linear model compensates for the excessive vertical strain rate at depth by lowering the constant strain rate in the upper region of the depth profile, producing a lower and potentially unrealistic estimate of layer thinning in this region. The result is a small negative trend in snow accumulation with depth in the upper part of the core, switching to a positive trend in the deeper parts. Overall, this produces a shallow concave bias in the snow accumulation rate estimates, with lower values at middle depths (Fig. 4a). Furthermore, there is more low-frequency power in the spectrum of the piece-wise linear snow accumulation rate time series compared to the equivalent spectrum for the powerlaw model, which is consistent with removal of the concave bias in vertical strain rates from the piece-wise linear model. 
Although we cannot exclude the possibility that this concave shape reflects a real environmental signal, we consider the power-law vertical strain rate profile to provide a more realistic snow accumulation rate reconstruction at DSS through its connection with the observed horizontal displacement data.

The vertical strain rate magnitude at DSS is not solely related to the horizontal displacement profile, rather, it is dependent on the shape of the profile, due to the threedimensional divergent nature of the DSS flow regime. The scaling parameter $s$ (Eq. 4) accounts for the effects of threedimensional flow in the power-law strain rate model. Accordingly, we base the subsequent analyses on this model. Note, however, that the differences between the snow accumulation rate histories derived using the two vertical strain rate models are small $\left(<0.04 \mathrm{~m} \mathrm{yr}^{-1}\right.$ IE for any year, see Fig. $\left.4 \mathrm{c}\right)$.

The shortcomings of the piece-wise linear vertical strain rate model, particularly for capturing variability on multicentennial and shorter timescales, are illustrated by comparing estimates of the vertical strain rate at the surface calculated using running $100 \mathrm{~m}$ subsets of the annual layer thickness data for each of the vertical strain rate models (Fig. 7). The vertical strain rates at the surface are more constant, and hence more internally consistent, for the power-law model. It should be noted that the results for both models are noisier in the upper portion of the ice-sheet (above $\sim 400 \mathrm{~m}$ ) and are not shown. This is driven by the significantly fewer annual data points in $100 \mathrm{~m}$ intervals from this zone due to the reduced effects of layer thinning near the surface and imperfections in the density model.

The estimated vertical strain rate at the surface for the two models are in reasonable agreement $\left(6.32 \times 10^{-4} \pm 7.8 \times\right.$ $10^{-6} \mathrm{yr}^{-1}$ and $6.57 \times 10^{-4} \pm 8.1 \times 10^{-6} \mathrm{yr}^{-1}$ for the piecewise linear and power-law models, respectively). However, both of these values differ significantly from the surface GPS-based value of $7.72 \times 10^{-4} \pm 3.1 \times 10^{-6} \mathrm{yr}^{-1}$ (Morgan et al., 1998). These differences might arise because the modelled vertical strain rates are estimated using data from only the upper portion of the ice sheet rather than the full ice sheet thickness.

\subsection{Snow accumulation history}

The mean snow accumulation rate of $0.688 \pm 0.130$ ( 1 standard deviation) $\mathrm{m} \mathrm{yr}^{-1} \mathrm{IE}\left(0.682 \pm 0.129 \mathrm{~m} \mathrm{yr}^{-1} \mathrm{IE}\right.$ for the piece-wise linear model) is in close agreement with previous estimates of 0.678 (Morgan et al., 1997), 0.680 (van Ommen et al., 2004) and $0.688 \mathrm{~m} \mathrm{yr}^{-1} \mathrm{IE}$ (van Ommen and Morgan, 2010). The assumption of no long-term trend in snow accumulation rate can be checked using the above long-term accumulation rate estimates. Specifically, each estimate is based on data fitting over different epochs; therefore, the similarity of these estimates suggests that either the assumption of no long-term trend in snow accumulation rate (see Sect. 3) is valid or that any trend in snow accumulation rate has been

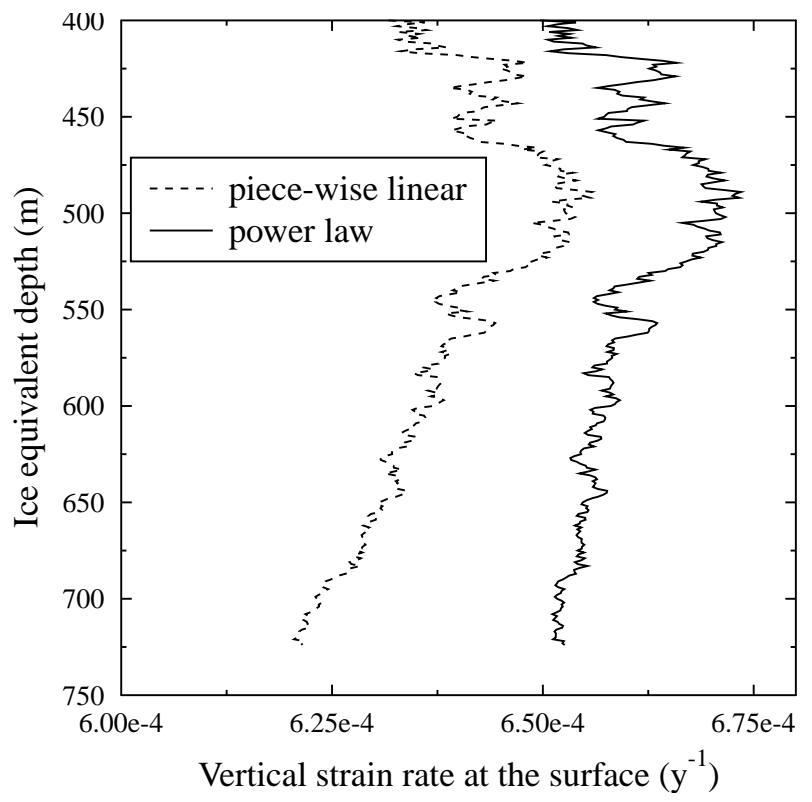

Figure 7. Inferred surface vertical strain rates from the piece-wise linear and power-law models. The surface strain rates are determined from annual layer thickness data from a $100 \mathrm{~m}$ depth interval centred on each ice equivalent depth value and the fixed long-term average annual snow accumulation rate specific to each model.

linear and constant over the last $2 \mathrm{kyr}$. Additionally, the uncertainty in the estimated vertical strain rate (and associated long-term snow accumulation rate) on the accumulation time history was assessed using a Monte Carlo simulation. For the piece-wise linear model, uncertainty in the accumulation record increases approximately linearly with depth, with an average value of $0.70 \%$ and a maximum of $1.77 \%$. Therefore, the assumption of a zero long-term snow accumulation trend does not rule out a trend of $0.88 \%$ per millennium.

The snow accumulation rate distribution has a standard deviation of $0.130 \mathrm{~m} \mathrm{yr}^{-1} \mathrm{IE}$ and is slightly, but significantly $(p<0.001$, D'Agostino et al., 1990) positively skewed (0.47), i.e. it has a long tail at higher snow accumulation rates (see Fig. 8). Additionally, the distribution has more mass in the tails than a normal distribution, with a nonmesokurtic ( $p<0.001$, D'Agostino et al., 1990) probability density function with slightly raised excess kurtosis (0.58).

Considering the 10-year low-pass filtered snow accumulation time series, the integrated snow accumulation excess $(I)$ can be defined as

$I=\int_{t_{0}}^{t_{1}}(\breve{a}(t)-\bar{a}) \mathrm{d} t$,

where $\breve{a}(t)$ is the low-pass filtered snow accumulation time series, and the epoch $t_{0}-t_{1}$ defines a contiguous period when $\breve{a}(t)$ is always above or below the long-term average snow accumulation $(\bar{a})$. The recent above-average snow accumu- 
Table 1. Integrated snowfall excess (Eq. 5) based on the 10-year low-pass filtered power-law-based DSS snowfall record. Positive values indicate a period with above-average low-pass filtered snowfall. Only integrated excesses larger in magnitude than $2 \mathrm{mIE}$ are shown.

\begin{tabular}{lr}
\hline Epoch (CE) & $\begin{array}{r}\text { Integrated snowfall } \\
\text { excess (m IE) }\end{array}$ \\
\hline $380-442$ & 3.323 \\
$663-704$ & -2.377 \\
$727-783$ & 3.056 \\
$1429-1468$ & -2.008 \\
$1970-2009$ & 2.597 \\
\hline
\end{tabular}

lation rate of 1970-2009 CE is the third largest period of integrated snow accumulation excess throughout the record (Fig. 4c), after 380-442 and 727-783 CE (see Table 1); however, it has the strongest anomaly as it occurs over a shorter time interval. Not only is the strength of the recent 39 year (1970-2009) snow accumulation rate anomaly uncommon, its duration is also atypical, with only 5 ( 3 positive and 2 negative) events of equal or longer duration, although decadalscale events are common with 74 events (33 positive and 41 negative) of at least a 10-year duration in the record. The three largest positive anomalies are all larger in magnitude than any of the negative anomalies in the record, possibly due to the positively skewed nature of the snow accumulation rate distribution. The three longest integrated low snowfall periods span 663-704, 933-975 and 1429-1468 CE. The combination of the low snowfall period for 663-704 CE followed by the high snowfall period of 727-783 CE results in a substantial trend in snow accumulation rate between the mid-7th century and the end of the 8th century. The continental-scale low snow-accumulation periods of 1250-1300 and 14201550 CE (Frezzotti et al., 2013) are reflected in the DSS record with strong negative $I$ (but are interspersed with short periods of above-average snow fall) for the epochs 12391302 and 1415-1522 CE. The continental-scale low snowaccumulation period of 1660-1790 CE is also recorded at the DSS site, although with a later commencement (1691 CE) and one short, but large $(I=0.623 \mathrm{mIE})$, positive anomaly between 1763 and $1772 \mathrm{CE}$.

There is no obvious relationship between anomalous accumulation periods, or trends associated with them, and the annually dated volcanic history of Plummer et al. (2012) because it is unlikely that the low-pass filtered accumulation record would reflect the high-frequency effect of atmospheric sulfate loading due to volcanic activity. Furthermore, there is no meaningful correlation $(r=-0.038, p>0.2)$ between Law Dome snow accumulation and the 1008-year Southern Annular Mode (SAM) record of Abram et al. (2014), consistent with the finding of van Ommen and Morgan (2010). Similarly, the 1000 -year Law Dome $\mathrm{CO}_{2}$ record of Rubino

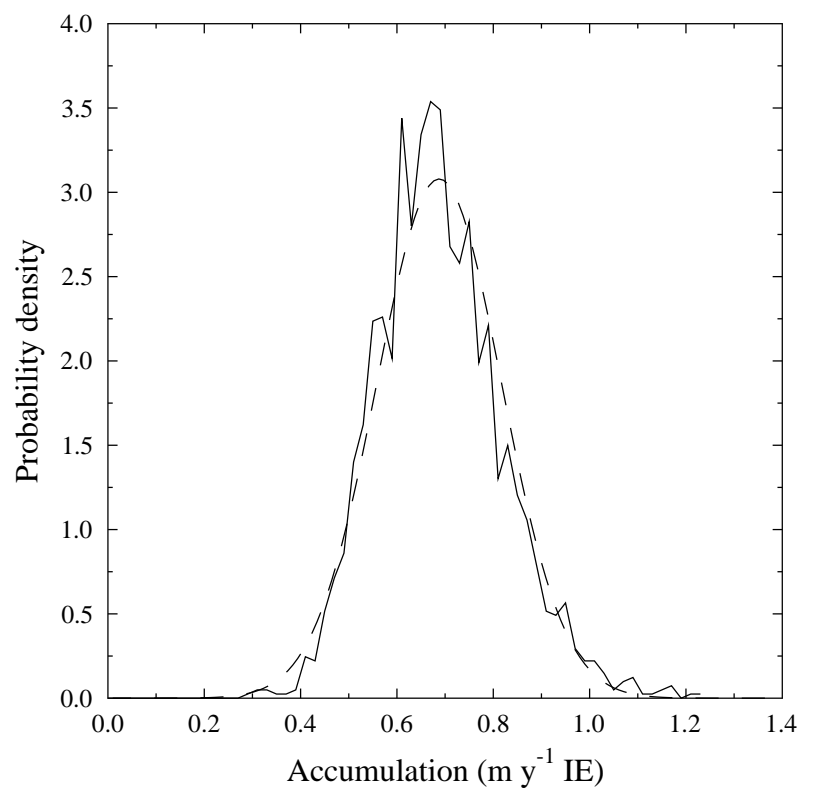

Figure 8. Probability density function for the power-law-based annual snow accumulation rate (solid line) and the equivalent normal distribution (dashed line). Note excess accumulation in the right hand tail of the power-law distribution.

et al. (2013) shows no obvious commonalities between $\mathrm{CO}_{2}$ and accumulation.

The accumulation series was compared with the annual $\delta^{18} \mathrm{O}$ isotope ratio at the site over the period of 174-2012 CE. Correlation analysis reveals that the two series are weakly correlated, with $r=0.227$. While only representing a common variance of $5 \%$, the result is highly statistically significant; the $95 \%$ confidence interval is [0.191-0.262], as computed using a method which accounts for autocorrelations (Ólafsdóttir and Mudelsee, 2014). A similar level of variance is found for 10-year low-pass filtered data, although the reduced effective degrees of freedom result in a larger $95 \%$ confidence interval [0.036-0.414]. The weak relationship between the isotope ratio and precipitation is consistent with earlier findings (van Ommen et al., 2004) which demonstrated a strong coupling of the isotope ratio and accumulation in the glacial period but not in the Holocene. Bromwich (1988) notes the importance of circulation intensity relative to thermodynamic control of moisture content in determining precipitation, and this is particularly important at Law Dome where cyclonic influence is large. The weak control of temperature over recent centuries also reflects other findings at other moderate to high accumulation sites (Frezzotti et al., 2013). Furthermore, van Ommen and Morgan (1997) show the isotope signal is affected by snow accumulation timing, deposition and surface reworking on short timescales which may also impact $\delta^{18} \mathrm{O}$-accumulation coherence.

Spectral analysis of the $2 \mathrm{kyr}$ annual snow accumulation rate record (Fig. 9) shows a number of significant period- 


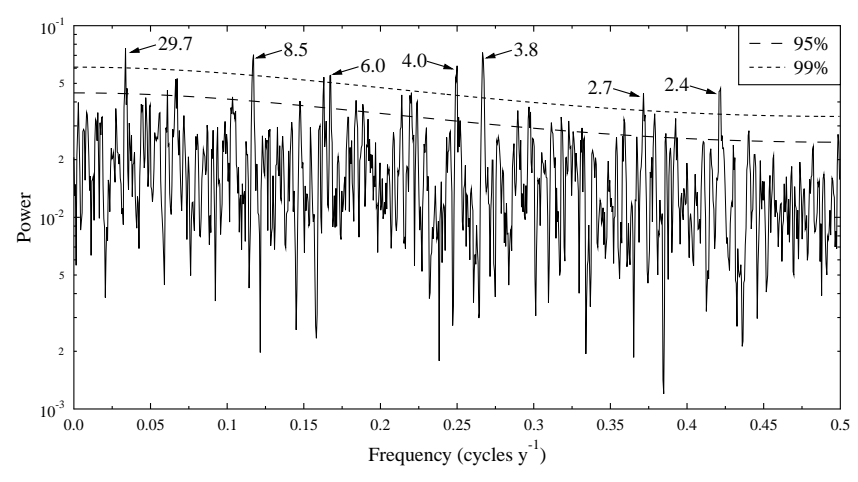

Figure 9. MultiTaper Method power spectrum (Ghil et al., 2002) of power-law-based snow accumulation rate time series using a resolution of 2 and 3 tapers. The period of spectral components above $99 \%$ significance are shown.

icities in the sub-decadal band of 2.4-8.5 years, while one 29.7-year period is also evident, which may be related to climate variability. The sub-decadal power at $2.4-8.5$ years is in the broadband of ENSO-type frequencies. An analysis of sea salts at Law Dome has previously shown an ENSO signal in the summer-period sea salts, with associated ENSO-band significant frequencies of 2.8, 4.4, 6.0 and 7.5 years (Vance et al., 2013). It is interesting to note that ENSO-type frequencies are also evident in the snow accumulation rate record despite there being no significant correlation between the snow accumulation rate record presented here and the Southern Oscillation Index over the epoch of 1870-2012 CE. The 29.7-year period is not seen in the summer sea salt record (Vance et al., 2013) but may be related to the IPO (Power et al., 1999), as a 1000-year reconstruction of the IPO has been produced recently using multiple Law Dome records. Snow accumulation rate was a necessary input parameter to this IPO reconstruction to produce a high skill reconstruction (Vance et al., 2015). The higher frequencies in the subdecadal band ( 2.4 and 2.7 years) are generally more intermittent throughout the $2 \mathrm{kyr}$ period (Fig. 10). The damping of these higher frequency signals may be a real climate signal, but may also result from noise associated with surface processes, such as the wind-blown redistribution of snowfall and the passage of sastrugi over the site. In contrast, the 29.7-year period is more persistent throughout the record, and there are multi-centennial epochs where this frequency is quite strong (e.g. 100-550, 750-1000 and 1500-2012 CE). Therefore, if the 29.7-year period is associated with the IPO, this suggests that the IPO signal has remained relatively steady at Law Dome for the past $2 \mathrm{kyr}$. This is further reinforced by Vance et al. (2015), who showed that both positive and negative phases of the IPO could be reconstructed with high skill over both the instrumental calibration period (1870-2009 CE) and the full millennial period spanning 1000-2009 CE.

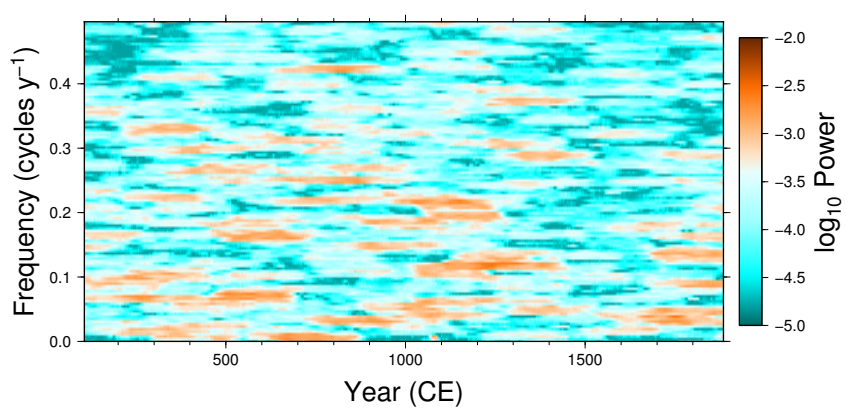

Figure 10. MultiTaper Method evolutive power spectrum of the calculated power law DSS snow accumulation rate time series using a resolution of 2 and 3 tapers and a bandwidth of 256 years.

Table 2. Correlation between the Law Dome snow accumulation record and shallow ice core records from Queen Maud Land (Fernandoy et al., 2010).

\begin{tabular}{lcccc}
\hline Core & $\begin{array}{c}\text { Latitude } \\
\left({ }^{\circ} \mathrm{S}\right)\end{array}$ & $\begin{array}{c}\text { Longitude } \\
\left({ }^{\circ} \mathrm{E}\right)\end{array}$ & $\begin{array}{c}\text { Epoch } \\
(\mathrm{CE})\end{array}$ & Correlation \\
\hline DML94C07_38 & -71.162 & -6.699 & $1979-2006$ & 0.389 \\
DML95C07_02 & -71.568 & -6.667 & $1979-2006$ & 0.318 \\
DML96C07_39 & -71.408 & -9.917 & $1979-2006$ & 0.167 \\
DML97C07_04 & -72.064 & -9.558 & $1979-2006$ & 0.423 \\
NM02C02_02 & -70.656 & -8.254 & $1980-2001$ & 0.340 \\
\hline
\end{tabular}

\subsection{Spatial variability}

The snow accumulation rate history from the DSS icecore captures broad-scale variability across a large region of East Antarctica, well beyond the immediate vicinity of the Law Dome summit (see Fig. 11), indicated by the spatial coherence of annual snow accumulation rate correlation from two climate reanalysis models. Temporal correlations at Law Dome are significant for both ERA-Interim $(r=0.6973, p<0.001)$ and RACMO2.1/ANT $(r=0.7604$, $p<0.001)$. The spatial pattern of the correlation between the modelled snow accumulation rate at Law Dome and elsewhere in Antarctica agrees well between the two models, although there is a much larger region of significant positive correlation in Queen Maud Land, East Antarctica using the RACMO2.1/ANT data set. The correlation with the RACMO2.1/ANT data set in this region is more likely representative, as RACMO2.1/ANT is strongly correlated to extensive observational data (Lenaerts et al., 2012) and snow accumulation records from shallow cores in the region are positively correlated with the Law Dome snow accumulation record (see Table 2). The magnitudes of the annual snow accumulation rates at Law Dome are also in reasonable agreement. For the 1979-2012 CE period covered by ERA-Interim, the mean calculated snow accumulation rate is $0.749 \pm 0.142$ compared to the ERAInterim modelled value of $0.713 \pm 0.136 \mathrm{~m} \mathrm{yr}^{-1} \mathrm{IE}$. The comparison with RACMO2.1/ANT is over the shorter pe- 


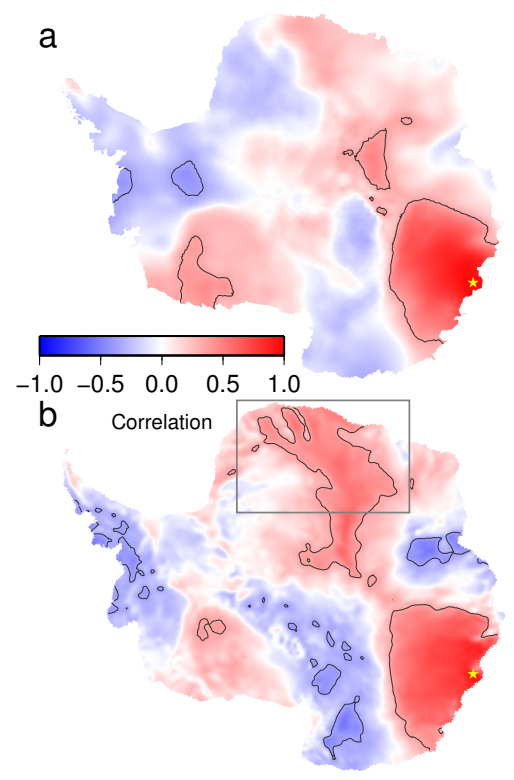

Figure 11. Spatial correlation maps for (a) ERA-Interim precipitation-evaporation (Dee et al., 2011) for 1979-2013 CE and (b) RACMO2.1/ANT surface mass balance (Lenaerts et al., 2012) for 1979-2010 CE. Contours show the $95 \%$ confidence level while yellow stars denote the location of DSS and the grey box shows Queen Maud Land.

riod of 1979-2010 CE, where the calculated mean rate is $0.759 \pm 0.141$ and the RACMO2.1/ANT mean value is $0.525 \pm 0.087 \mathrm{~m} \mathrm{yr}^{-1}$ IE. It is worth noting that this is a predominantly positive/neutral IPO period and these spatial relationships could change during strongly negative IPO periods given the clear IPO signal that is present at Law Dome (Vance et al., 2015).

The Law Dome regional accumulation map exhibits largescale spatial coherence Fig. 11, with an average $e$-folding distance of $900 \mathrm{~km}$ (distance at which the correlation drops to $e^{-1}$ ). This suggests that inter-annual variability in snowfall is dominated by year-to-year changes in the large-scale atmospheric dynamical forcing, in agreement with a teleconnection pattern linking Law Dome accumulation with a zonal wave three index (van Ommen and Morgan, 2010). The spatial correlation between $500 \mathrm{hPa}$ geopotential height and the snow accumulation rate (Fig. 12) shows a quasi-ZW3 pattern, however the Australian and African high pressure poles are contracted towards Antarctica. Principal component analysis (PC) of the Southern Hemisphere $500 \mathrm{hPa}$ geopotential height field supports this. While PC1 (31\%) and PC2 $(15 \%)$ represent most of the dominant annular variability in the Southern Hemisphere $500 \mathrm{hPa}$ geopotential height, in the Law Dome region there is little correlation between these first two principle components and accumulation. In contrast, PC3 (11\%) $(r=0.5, p<0.01$ for the Law Dome region) shows a strong correlation with Law Dome accumulation (Fig. 12 inset). This local modulation of the large-scale

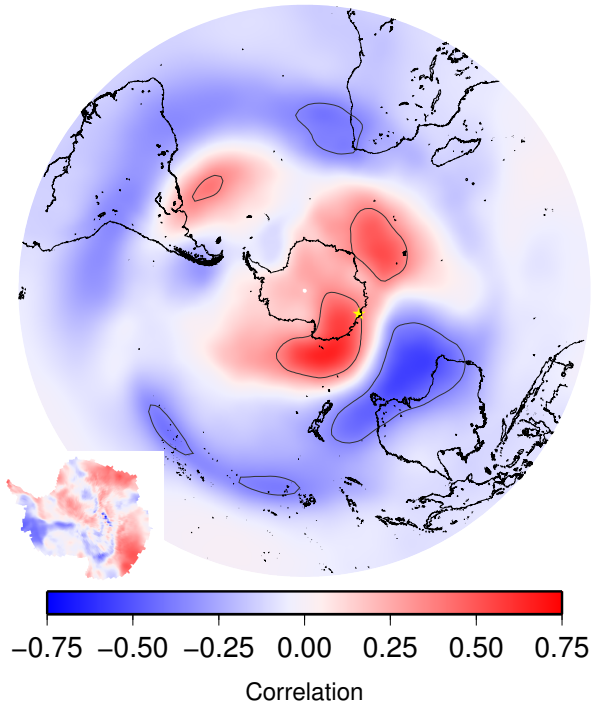

Figure 12. Spatial correlation map for ERA-Interim $500 \mathrm{hPa}$ geopotential height (Dee et al., 2011) and power-law-based snow accumulation rate for 1979-2012 CE. Contours show the $95 \%$ confidence level while the yellow star denotes the location of DSS. Inset: third principal component of the Southern Hemisphere $500 \mathrm{hPa}$ geopotential height correlated with power-law-based snow accumulation rate for 1979-2012 CE.

variability may represent a tropical signal as demonstrated by the relationship between PC3 and the Pacific-South American modes (Mo and Paegle, 2001). This is a further line of evidence that Law Dome ice cores are not only sensitive to the dominant annular signal centred over West Antarctica, but also preserve tropical and mid-latitude Pacific and Indian Ocean signals as shown by Vance et al. $(2013,2015)$.

It should be noted that the snow-preserved accumulation record is influenced by local factors such as wind removal and potential regional (Law Dome) variations driven by interactions between weather systems and local orography. Wind speeds at Law Dome Summit are generally low (Morgan et al., 1997) and net wind removal is not believed to be a major influence at this site. However, the strong orographically driven accumulation gradient across Law Dome could conceivably lead to a local signal in accumulation variability if the climatology of cyclonic systems and wind tracks changes. Such spatial distribution changes still represent a climate signal, rather than an amplitude modulation of a relatively stable spatial distribution. Therefore, these influences might reduce coherence between the Law Dome accumulation series and the broader Wilkes Land region. The observed coherence with the precipitation minus evaporation fields in the reanalyses discussed above suggests that the local influences are not significant. 


\section{Conclusions}

Two thousand years (22 BCE to 2012 CE) of annual snow accumulation rates have been calculated for Law Dome, which extends the length of the previous 750-year record. To deconvolve the effects of ice sheet thinning on calculated snow accumulation rate profiles, two vertical strain rate models were evaluated, of which a power-law model proved the most appropriate. The long-term accumulation rate of $0.688 \pm 0.130 \mathrm{~m} \mathrm{yr}^{-1}$ IE for this model is in agreement with previous estimates, and further supports the notion that there is no long-term trend in snow accumulation rates, or that any trend is constant and linear over the period of measurement. Several anomalous periods of accumulation exist in the record, most notably the periods of 380-442, 727-783 and 1970-2009 CE (high accumulation) and 663-704, 933975 and 1429-1468 CE (low accumulation). The record has wide-reaching relevance, indicated by a spatial coherence in correlations with two climate reanalysis models showing the capture of large-scale variability and possible links to tropical and higher-latitude dynamical forcing. Furthermore, significant periodicities were observed in the record which were broadly consistent with ENSO- and IPO-type variability, suggesting these patterns play an important role in the delivery of mass to the Law Dome region. The publication of this accumulation record will allow for the investigation, by both this research group and others, of relationships between local meteorologically and environmentally sensitive variables (such as stable water isotopes, methanesulfonic acid and sea-salt ions) as well as more regional and hemispheric teleconnections. Specifically this research group has work underway updating the DSS stable water isotope record (and will publish comparisons with this accumulation record as part of that work) and is further studying the use of the DSS accumulation record as a proxy for eastern Australian palaeoclimate.

\section{The Supplement related to this article is available online at doi:10.5194/cp-11-697-2015-supplement.}

Acknowledgements. The Australian Antarctic Division provided funding and logistical support (ASS projects 757, 4061, 4062). This work was supported by the Australian Government's Cooperative Research Centres Programme through the Antarctic Climate and Ecosystems Cooperative Research Centre (ACE CRC). ECMWF ERA-Interim data used in this study have been obtained from the ECMWF data server.

Edited by: V. Masson-Delmotte

\section{References}

Abram, N. J., Mulvaney, R., Vimeux, F., Phipps, S. J., Turner, J., and England, M. H.: Evolution of the Southern Annular Mode during the past millennium, Nat. Clim. Change, 4, 1-6, doi:10.1038/NCLIMATE2235, 2014.

Bamber, J. L., Gomez-Dans, J. L., and Griggs, J. A.: A new 1 km digital elevation model of the Antarctic derived from combined satellite radar and laser data - Part 1: Data and methods, The Cryosphere, 3, 101-111, doi:10.5194/tc-3-101-2009, 2009.

Bromwich, D.: Snowfall in high southern latitudes, Rev. Geophys., 26, 149-168, 1988.

D’Agostino, R., Belanger, A., and D'Agostino, Jr., R.: A suggestion for using powerful and informative tests of normality, Am. Stat., 44, 316-321, 1990.

Dansgaard, W. and Johnsen, S.: A flow model and a time scale for the ice core from Camp Century, Greenland, J. Glaciol., 8, 215223, 1969.

Dee, D. P., Uppala, S. M., Simmons, A. J., Berrisford, P., Poli, P., Kobayashi, S., Andrae, U., Balmaseda, M. A., Balsamo, G., Bauer, P., Bechtold, P., Beljaars, A. C. M., van de Berg, L., Bidlot, J., Bormann, N., Delsol, C., Dragani, R., Fuentes, M., Geer, A. J., Haimberger, L., Healy, S. B., Hersbach, H., Hólm, E. V., Isaksen, L., Kå llberg, P., Köhler, M., Matricardi, M., McNally, A. P., Monge-Sanz, B. M., Morcrette, J.-J., Park, B.-K., Peubey, C., de Rosnay, P., Tavolato, C., Thépaut, J.-N., and Vitart, F.: The ERA-Interim reanalysis: configuration and performance of the data assimilation system, Quarterly J. Roy. Meteorol. Soc., 137, 553-597, doi:10.1002/qj.828, 2011.

Fernandoy, F., Meyer, H., Oerter, H., Wilhelms, F., Graf, W., and Schwander, J.: Stable-isotope ratios and accumulation rates of four firn cores from the Dronning Maud Land, Antarctica, doi:10.1594/PANGAEA.753185, supplement to: Fernandoy, F., Meyer, H., Oerter, H., Wilhelms, F., Graf, W., and Schwander, J.: Temporal and Spatial variation of stable-isotope ratios and accumulation rates in the hinterland of Neumayer station, East Antarctica, J. Glaciol., 56, 673-687, 2010.

Frezzotti, M., Scarchilli, C., Becagli, S., Proposito, M., and Urbini, S.: A synthesis of the Antarctic surface mass balance during the last 800 years, The Cryosphere, 7, 303-319, doi:10.5194/tc-7303-2013, 2013.

Ghil, M., Allen, M. R., Dettinger, M. D., Ide, K., Kondrashov, D., Mann, M. E., Robertson, A. W., Saunders, A., Tian, Y., Varadi, F., and Yiou, P.: Advanced spectral methods for climatic time series, Rev. Geophys., 40, 41, doi:10.1029/2001RG000092, 2002.

Hutter, K.: Dynamics of glaciers and large ice masses, Ann. Rev. Fluid Mechan., 14, 87-130, 1982.

Lenaerts, J. T. M., van den Broeke, M. R., van de Berg, W. J., van Meijgaard, E., and Kuipers Munneke, P.: A new, high-resolution surface mass balance map of Antarctica (1979-2010) based on regional atmospheric climate modeling, Geophys. Res. Lett., 39, $1-5,2012$.

Lliboutry, L. A.: A critical review of analytical approximate solutions for steady state velocities and temperature in cold ice sheets, Zeitschift fur Gletscherkunde und Glazialgeologie Bd., 15, 135-148, 1979.

Mo, K. C. and Paegle, J. N.: The Pacific-South American modes and their downstream effects, Internat. J. Climatol., 21, 1211-1229, 2001. 
Morgan, V., Wookey, C., LI, J., van Ommen, T., Skinner, W., and Fitzpatrick, M.: Site information and initial results from deep ice drilling on Law Dome, Antarctica, J. Glaciol., 43, 3-10, 1997.

Morgan, V., van Ommen, T., Elcheikh, A., and Jun, L.: Variations in shear deformation rate with depth at Dome Summit South, Law Dome, East Antarctica, Ann. Glaciol., 27, 135-139, 1998.

Ólafsdóttir, K. B. and Mudelsee, M.: More accurate, calibrated bootstrap confidence intervals for estimating the correlation between two time series, Mathemat. Geosci., 46, 411-427, 2014.

Paterson, W.: The Physics Of Glaciers (Third Edition), Butterworth Heinemann, Oxford, 1994.

Plummer, C. T., Curran, M. A. J., van Ommen, T. D., Rasmussen, S. O., Moy, A. D., Vance, T. R., Clausen, H. B., Vinther, B. M., and Mayewski, P. A.: An independently dated 2000-yr volcanic record from Law Dome, East Antarctica, including a new perspective on the dating of the 1450s CE eruption of Kuwae, Vanuatu, Clim. Past, 8, 1929-1940, doi:10.5194/cp-8-1929-2012, 2012.

Power, S., Casey, T., Folland, C., Colman, A., and Mehta, V.: Interdecadal modulation of the impact of ENSO on Australia, Clim. Dynam., 15, 319-324, 1999.

Raphael, M. N.: A zonal wave 3 index for the Southern Hemisphere, Geophys. Res. Lett., 31, L23212, doi:10.1029/2004GL020365, 2004.

Roberts, J. L., Warner, R. C., Young, D., Wright, A., van Ommen, T. D., Blankenship, D. D., Siegert, M., Young, N., Tabacco, I. E., Forieri, A., Passerini, A., Zirizzotti, A., and Frezzotti, M.: Refined broad-scale sub-glacial morphology of Aurora Subglacial Basin, East Antarctica derived by an ice-dynamics-based interpolation scheme, The Cryosphere, 5, 551-560, doi:10.5194/tc-5551-2011, 2011.
Rubino, M., Etheridge, D. M., Trudinger, C. M., Allison, C. E., Battle, M. O., Langenfelds, R. L., Steele, L. P., Curran, M., Bender, M., White, J. W. C., Jenk, T. M., Blunier, T., and Francey, R. J.: A revised 1000 year atmospheric $\delta 13 \mathrm{C}-\mathrm{CO}_{2}$ record from Law Dome and South Pole, Antarctica, J. Geophys. Res.-Atmos., 118, 8482-8499, 2013.

van Ommen, T. D. and Morgan, V.: Calibrating the ice core paleothermometer using seasonality, J. Geophys. Res., 102, 93519357, 1997.

van Ommen, T. D. and Morgan, V.: Snowfall increase in coastal East Antarctica linked with southwest Western Australian drought, Nat. Geosci., 3, 267-272, 2010.

van Ommen, T. D., Morgan, V., and Curran, M. A. J.: Deglacial and Holocene changes in accumulation at Law Dome, East Antarctica, Ann. Glaciol., 39, 359-365, 2004.

Vance, T., Roberts, J., Plummer, C., Kiem, A., and van Ommen, T.: Interdecadal Pacific variability and Australian mega-droughts over the last millennium, Geophys. Res. Lett., 42, 129-137, 2015.

Vance, T. R., van Ommen, T. D., Curran, M. A. J., Plummer, C. T., and Moy, A. D.: A Millennial Proxy Record of ENSO and Eastern Australian Rainfall from the Law Dome Ice Core, East Antarctica, J. Climate, 26, 710-725, 2013. 